\title{
Rituals Alleviate Grieving for Loved Ones, Lovers, and Lotteries
}

\section{Citation}

Norton, Michael I., and Francesca Gino. "Rituals Alleviate Grieving for Loved Ones, Lovers, and Lotteries." Journal of Experimental Psychology: General (forthcoming).

\section{Permanent link}

http://nrs.harvard.edu/urn-3:HUL.InstRepos:10683152

\section{Terms of Use}

This article was downloaded from Harvard University's DASH repository, and is made available under the terms and conditions applicable to Open Access Policy Articles, as set forth at http:// nrs.harvard.edu/urn-3:HUL.InstRepos:dash.current.terms-of-use\#OAP

\section{Share Your Story}

The Harvard community has made this article openly available.

Please share how this access benefits you. Submit a story.

Accessibility 
Running Head: RITUALS AND GRIEF

\title{
Rituals Alleviate Grieving for Loved Ones, Lovers, and Lotteries
}

\author{
Michael I. Norton and Francesca Gino
}

Harvard Business School

Word count: 5,254

Michael I. Norton and Francesca Gino, Harvard Business School, Soldiers Field Road, Boston, MA, 02163; mnorton@hbs.edu, fgino@hbs.edu.We thank Max Bazerman, Eugene Caruso, Zoe Chance, David DeSteno, Jane Risen, Maurice Schweitzer, Chen-Bo Zhong, and members of the GiNorton lab group for their comments, and Austin Crumpton, Jennifer Fink, Mindi Rock, Leslie Talbott and Ruth Winecoff for their assistance. 


\begin{abstract}
Three experiments explored the impact of mourning rituals after losses - of loved ones, lovers, and lotteries - on mitigating grief. Participants who were directed to reflect on past rituals or who were assigned to complete novel rituals after experiencing losses reported lower levels of grief. Increased feelings of control after rituals mediated the link between use of rituals and reduced grief after losses, and the benefits of rituals accrued not only to individuals who professed a belief in rituals' effectiveness but also those who did not. Although the specific rituals in which people engage after losses vary widely by culture and religion - and among our participants - our results suggest a common psychological mechanism underlying their effectiveness: regained feelings of control.
\end{abstract}


Rituals of mourning in the face of loss - from the death of loved ones to the end of meaningful relationships to losses in wars and competitions - are ubiquitous across time and cultures (Ashenburg, 2004; Durkheim, 1912; Stroebe, Hansson, Stroebe, \& Schut, 2001). The most frequently studied rituals are those surrounding religion: people turn to prayer after negative life events such as September $11^{\text {th }}$, for example, and prayer has been associated with improved coping (Ai, Tice, Peterson, \& Huang, 2005; Pargament, 1997; Sherkat \& Reed, 1992). So common is this instinct to devise rituals in the face of negative events that the wide variety of known mourning rituals can even be contradictory: crying near the dying is viewed as disruptive by Tibetan Buddhists but as a sign of respect by Catholic Latinos; Hindu rituals stress the removal of hair when mourning while growing hair (a beard) is the preferred ritual for Jewish males (Clements, 2003; Kemp \& Bhungalia, 2002). Ritualistic behavior manifests not just in religious practice, however, but is present across domains of human life, providing order and stability while marking change - especially in times of chaos and disorder (Romanoff, 1998; Turner, 1969). Integrating prior conceptualizations (Crew \& Boutcher, 1986; Cohn, 1990; Rook, 1985), we define a ritual as a symbolic activity that is performed either before or after a meaningful event which is intended to achieve some desired outcome - from alleviating grief to winning a competition to making it rain. Often, rituals occur in fixed, repeated sequences, and in communal or religious settings; as our data below demonstrate, however, people often create "everyday" rituals that are performed in the absence of such factors, but which still meet the definition of a symbolic behavior performed to induce some desired effect.

Why are rituals so ubiquitous, and, given that they are unlikely to be effective in producing some desired outcomes (such as actually influencing the production of rain), why might they improve coping after loss? Despite the variance in the form that rituals take, we 
propose that a common psychological mechanism underlies their effectiveness: a restoration of feelings of control that losses impair. Indeed, people who suffer losses often report feeling "out of control" (Low, 1994) and actively try to regain control when they feel it slipping away (Brehm, 1966); feeling in control in turn is associated with increased well-being, physical health, and coping ability (Glass \& Singer, 1972; Klein, Fencil-Morse, \& Seligman, 1976; Rodin \& Langer, 1977). Some qualitative data offer initial evidence for the link between rituals and control; for example, the extent to which athletes and fisherman engage in rituals is related to the unpredictability of their jobs (Gmelch, 1971; Malinowski \& Redfield, 1948; see Whitson \& Galinsky, 2008). We suggest that the use of rituals serves as a compensatory mechanism designed to restore feelings of control after losses, and that this increased feeling of control contributes to reduced grief.

We propose that people turn to rituals after diverse kinds of losses - in the experiments below, of loved ones, lovers, and lotteries - in order to reestablish their feelings of control and mitigate their general negative feelings, such that the feelings of control brought about by rituals mediate the relationship between ritual use and reduced grief. Despite the many differences in the specific rituals that people perform after experiencing losses, and the diversity of emotions that accompany different types of losses, we propose that a common psychological mechanism perceived control - underlies the effectiveness of rituals in alleviating grief.

\section{Pilot Study}

To gain a better understanding of the type and variety of rituals people use to cope with their losses, we conducted a pilot study in which participants provided descriptions of rituals in which they engaged after experiencing a loss. Individuals $\left(N=76 ; M_{\text {age }}=37.92, S D=10.79 ; 43 \%\right.$ male) from a pool of subjects managed by a public university in the southern United States were 
asked to recall a significant loss - either the death of a loved one or the end of a close relationship - and write in detail about how they coped with that loss, as well as to recall and write about a ritual in which they engaged to cope with that loss.

Participants' descriptions of their rituals revealed wide variety, encompassing changes in habits, attitudes, behaviors, and preferences (see Table 1 for examples). For instance, some participants reported engaging in the person's favorite activities, while others reported avoiding those activities. Two blind coders read the descriptions and noted whether: 1) the ritual was communal or carried out individually, 2) the ritual involved public or private actions, and 3) the ritual was religious or not. The two coders agreed $93 \%$ of the time; disagreements were resolved by a third coder. Few rituals (5\%) were specifically religious in nature, while just $10 \%$ were performed in public and just 5\% performed communally. Thus most of the rituals we observed were private, "everyday" rituals that were unique to an individual - as opposed to publiclyperformed, commonly-utilized rituals.

\section{Experiment 1: Control as Psychological Mechanism}

In Experiment 1, we examined the influence of such "everyday" rituals on perceived control and grief. We asked all participants to recall and write in detail about one of two significant losses: the death of a loved one or the end of a close relationship. Some participants were further assigned to include a description of a ritual in which they engaged after experiencing that loss. We used a recall task due to the obvious impossibility of producing these kinds of losses in a laboratory setting; this reminiscence-based methodology has been used successfully in previous research to study the emotional consequences of real-world experiences (Strack, Schwarz, \& Gschneidinger, 1985; Van Boven \& Gilovich, 2003). Upon completion of the writing task, participants completed a survey which included questions about their feelings of 
grief about the person they lost (our primary dependent measure). While previous research has documented a positive impact of writing about traumatic events (Nolen-Hoeksema \& Larson, 1999; Pennebaker \& Chung, 2007), we predicted a benefit of writing about rituals over and above simply writing about loss.

We also assessed our proposed mechanism underlying the impact of rituals: the restorative nature of rituals on the feelings of control that are undermined by losses. We predicted that individuals who reflected on the rituals they performed to cope with their losses would be more likely to report feeling in control at the time they performed those rituals, and that these heightened feelings of control would be related to reduced grief about the loss.

\section{Method}

Participants. Two-hundred forty-seven individuals $\left(M_{\text {age }}=32.60, S D=8.88 ; 42 \%\right.$ male; 18\% students) recruited from Amazon's Mechanical Turk participated in this study in exchange for $\$ 2$.

Procedure. Experiment 1 employed two between-subjects manipulations: type of loss (relationship ending vs. death) and presence of rituals (ritual vs. no ritual). Participants were randomly assigned to one of these four conditions. Across conditions, they were asked to recall a loss and write about it for 5 to 10 minutes.

Participants in the relationship-ending conditions received the following instructions:

(Both ritual and no-ritual conditions) Please think back to a relationship you truly cared about that ended in the past. Think of the time you spent with the person before the relationship ended and of how you felt when the relationship ended. Please describe this event in detail. What was it like to be in this situation? What thoughts and feelings did you experience?

Participants in the death conditions read:

(Both ritual and no ritual conditions) Please think back to a person you truly cared about who you lost in the past. Think of the time you spent with the person before the person 
passed away and of how you felt when the death occurred. Please describe this event in detail. What was it like to be in this situation? What thoughts and feelings did you experience?

Participants assigned to the ritual conditions also read the following instruction, which appeared as part of the instructions described above:

((both relationship-ending and death) As part of your description, please describe a RITUAL you engaged in after you experienced the loss (e.g., you stopped going to a place that was meaningful for your relationship with this person for a while, you stopped wearing clothes he/she liked for a while). Please provide a detailed description.

Participants then completed our measure of perceived control. The instructions read: "Now please answer the following questions about the event you wrote about, and the activities you may have engaged in after it. We realize it may be difficult for you to remember exactly how you felt, but please answer the questions as best as you can." We used four items to assess participants' retrospective feelings of lack of control, on a 7-point scale ( $1=$ not at all to $7=$ very much): (1) To what extent did you feel out of control? (2) To what extent did you feel a sense of helplessness? (3) To what extent did you feel things were in check? (reverse-coded) and (4) To what extent did you feel powerless? We averaged these items to create a composite measure of perceived lack of control $(\alpha=.83)$.

Finally, participants answered questions about their feelings toward the person they lost. We adapted Prigerson et al.’s (1995) grief scale. Participants answered sixteen questions (e.g., I feel that life is empty without this person) on a 5 -point scale $(1=$ never, $2=$ rarely, $3=$ sometimes, $4=$ often, $5=$ always $)$. We averaged these items to create a composite measure of grief $(\alpha=.92)$.

\section{Results and Discussion}

Perceived lack of control. As predicted, participants reported lower retrospective feelings of lack of control in the ritual condition $(M=5.04, S D=1.48)$ than in the no-ritual 
condition $(M=5.40, S D=1.22), F(1,243)=4.43, p=.036, \eta_{p}{ }^{2}=.018$. There was no significant effect of type of loss $(p=.95)$ and no interaction between use of rituals and type of loss $(p=.72)$.

Grief. Participants also reported reduced grief in the ritual condition $(M=2.12, S D=0.73)$ compared to the no-ritual condition $(M=2.37, S D=0.83), F(1,243)=6.39, p=.012, \eta_{p}{ }^{2}=.026$; the main effect of type of loss was not significant $(p=.74)$, nor was the interaction $(p=.25)$.

Mediation analysis. We expected reduced retrospective feelings of lack of control to mediate the impact of rituals on grief. The effect of rituals on grief was significantly reduced (from $\beta=-.16, p=.014$, to $\beta=-.12, p=.054$ ) when participants' retrospective feelings of lack of control were included in the equation, and these feelings significantly predicted grief $(\beta=.29$, $p<.001$ ), controlling for type of loss. ${ }^{1}$ The $95 \%$ bias-corrected confidence intervals for the size of the indirect effect excluded zero $(-0.14,-0.01)$, suggesting a significant indirect effect (MacKinnon, Fairchild, \& Fritz, 2007). These results indicate that, as predicted, perceived control mediated the effect of recalling rituals on grief.

Word count. Given the benefits of writing about traumatic events (Nolen-Hoeksema \& Larson, 1999; Pennebaker \& Chung, 2007), we wanted to demonstrate that writing about rituals produced benefits over and above the effect of simply writing about losses. We first examined whether participants wrote more in the ritual conditions than in the no-ritual conditions. A 2 (type of loss) and X 2 (presence of rituals) between-subjects ANOVA revealed no main effect for type of $\operatorname{loss}\left(F(1,243)<1, p=.33, \eta_{p}{ }^{2}=.004\right)$ or interaction $\left(F(1,243)<1, p=.54, \eta_{p}{ }^{2}=.002\right)$; there was a marginally significant effect for presence of rituals $\left(M_{\text {ritual }}=151.74\right.$ words vs. $M_{n o-}$ ritual $=132.32$ words, $\left.F(1,243)=2.69, p=.10, \eta_{p}{ }^{2}=.011\right)$. Given this trend, we conducted two 2 X 2 ANOVAs with grief and retrospective feelings of lack of control as the dependent measures while controlling for number of words. Importantly, our results were similar; as before, the only

\footnotetext{
${ }^{1}$ We control for type of loss in all mediational analyses.
} 
significant effect was of our ritual manipulation (for grief, $F(1,242)=6.24, p=.013, \eta_{p}{ }^{2}=.025$; for lack of control, $\left.F(1,242)=4.20, p=.042, \eta_{p}{ }^{2}=.017\right)$. In both analyses, number of words was not a significant covariate $\left(F(1,242)<1, p=.92, \eta_{p}{ }^{2}=.000\right.$ and $F(1,242)<1, p=.70, \eta_{p}{ }^{2}=.001$, respectively). Together, these results suggest that rituals produce benefits beyond those generated by writing alone.

\section{Experiment 2: Losses in the Laboratory}

Experiment 2 had four primary goals. First, Experiment 1 suggests that a wide variety of everyday rituals that people devise and perform after losses are effective in assuaging grief; as a strong test of the impact of rituals on grief, Experiment 2 examines whether even novel rituals assigned by an experimenter can decrease grief. Second, while Experiment 1 demonstrated that reflecting on past rituals can alleviate mourning, Experiment 2 is a behavioral study in which participants engaged or did not engage in a ritual immediately after experiencing a third kind of loss: losing a lottery. Third, Experiment 2 explores whether the benefits of rituals emerge not only for people who believe in rituals and tend to engage in them, but also those who do not have such beliefs and do not commonly use rituals. Finally, one possible reason for people reporting reduced grief after being asked about rituals is experimenter demand: "If they are asking me how I feel after rituals, perhaps they are implying that I should feel better." As a result, we assessed perceptions of demand to show that rituals have benefits independent from experimenter demand.

\section{Method}

Participants. One-hundred nine individuals $\left(M_{a g e}=21.47, S D=2.64 ; 48 \%\right.$ male $)$ from a pool of subjects managed by a private university in the northeastern United States participated in 
the study for pay. Participants received a $\$ 15$ show-up fee and had the opportunity to earn an additional \$200.

Design and Procedure. Experiment 2 employed one between-subjects manipulation - no ritual vs. ritual - and included both an online portion and a laboratory portion. After signing up for the study, participants were asked to complete an online survey at least three days prior to the laboratory portion of the study. The survey included demographic questions (i.e., age, gender and ethnicity), some filler questions (e.g., "which characteristic most fits you?" athletic, intelligent, social, hard-working), and measures assessing both the frequency with which respondents used rituals and their belief in their effectiveness.

Two questions assessed participants' frequency of engaging in rituals, on 5-point scales ( $1=$ not at all, $2=$ very rarely, $3=$ occasionally, $4=$ frequently, and $5=$ very frequently): (1) How often do you engage in rituals before performing an important activity (e.g., an exam or a competition)? (2) How often do you engage in rituals after a meaningful event (e.g., a death of a loved one)? We averaged these items to form a composite measure of use of rituals $(\alpha=.65)$. To assess beliefs about rituals' effectiveness, participants indicated the extent to which they believed that "performing rituals influences the way people feel (e.g., more calm, less sad, etc.)" on a 7point scale $(1=$ not at all to $7=$ to a great extent $)$.

The subsequent laboratory sessions had between 9 to 15 participants per session. At the beginning of each session, the experimenter informed participants that one participant in the room would be randomly chosen as a lottery winner and that this participant would receive $\$ 200$ and be allowed to leave the session early. In order to make the loss personally relevant, participants were asked to write a short essay about why they cared about winning the $\$ 200$ and how they would spend it. The experimenter then randomly chose one participant and gave 
$\mathrm{him} / \mathrm{her} \$ 200$ in cash; this participant was dismissed from the experiment. The remaining participants were sent into individual cubicles and randomly assigned to one of the two experimental conditions. Participants assigned to the ritual condition read:

Your next task is to engage in a ritual. Previous research has found that people often engage in rituals after a loss. Please engage in each of the following steps involved in the ritual. The experimenter will let you know when time is up.

Step 1: Please draw how you currently feel on the piece of paper on your desk for two minutes; Step 2. Please sprinkle a pinch of salt on the paper with your drawing; Step 3. Please tear up the piece of paper; Step 4. Now please count up to ten in your head five times. Step 5. You have now completed this task.

Participants assigned to the no-ritual condition engaged in a filler task for the same amount of time. Specifically, they were told to draw how they currently felt on a piece of paper for a few minutes.

Participants then completed a 5-item measure of perceived control (e.g., "to what extent are you able to have some control over what happens in the world?") on a 7-point scale (1=very little control to 7=a great deal of control, from Fast, Gruenfeld, Sivanathan, \& Galinsky, 2009; $\alpha=.80$ ). Next, participants indicated their agreement with three items assessing their grief (e.g., "I can't help feeling angry and upset about the fact that I did not win the \$200") on a 7-point scale (1=strongly disagree to $7=$ strongly agree; $\alpha=.87$ ).

Finally, participants answered a question that assessed potential demand effects, by rating the extent to which they thought the experimenter wanted them to feel better about the loss they had experienced in the random draw, on a 7 -point scale ( $1=$ not at all to $7=$ to a large extent).

\section{Results and Discussion}

Perceived control. As predicted, feelings of control varied by condition, $t(98)=3.23$, $p=.002$. Participants reported higher feelings of control in the ritual condition $(M=3.35, S D=1.07)$ than in the no-ritual condition $(M=2.67, S D=1.03)$. 
Grief. In addition, participants reported lower levels of grief about losing the lottery in the ritual condition $(M=2.95, S D=1.36)$ than in the no-ritual condition $(M=4.07, S D=1.78)$, $t(98)=-3.51, p=.001$.

Mediation. Providing further support for the mechanism reported in Experiment 1, participants' feelings of perceived control mediated the effects of rituals on reduced grief: the effect of rituals was significantly reduced (from $\beta=-.33, p=.001$, to $\beta=-.26, p=.01$ ) when perceived control was included in the equation, and perceived control significantly predicted grief $(\beta=-.25, p=.013$ ). A bootstrap analysis showed that the $95 \%$ bias-corrected confidence intervals for the size of the indirect effect excluded zero $(-0.57,-0.07)$, suggesting a significant indirect effect (MacKinnon et al., 2007).

Beliefs in rituals. We next tested whether these benefits of rituals would accrue to only individuals who had reported using and believing in rituals, or if the effects of rituals would emerge regardless of these factors. We conducted separate regression analyses with our manipulation (ritual vs. no ritual), the two measures of participants' usage of and belief in rituals, and the interaction between our manipulation and each measure. For grief, we observed no effect of frequency or belief $(\beta s=-.08$ and $.11, p s=.55$ and .46$)$, nor was there a significant interaction of frequency or belief with presence of rituals ( $\beta s=.24$ and $-27, p s=.40$ and .48 ). For control, there was an overall effect of frequency $(\beta=.30, p=.03)$ - such that regardless of their condition, participants who engaged in rituals more frequently felt more in control - and no effect of belief ( $\beta=.13, p=.41$ ); most importantly for our account, there were again no interactions of frequency or belief with presence of rituals $(\beta s=-.27$ and $-.29, p s=.34$ and .45$)$. This lack of moderation for frequency and belief across both grief and control suggests that rituals do not require belief in order to yield benefits. 
Demand effects. Participants' belief that the experimenter wanted them to feel better about their loss was not affected by our manipulation $\left(M_{\text {ritual }}=3.52, S D=1.61\right.$, vs. $M_{\text {no-ritual }}=3.26$, $S D=1.66, t(98)<1, p=.43)$. In addition, we conducted two ANCOVAs with grief and perceived control as the dependent measures while controlling for the demand effect item. These analyses revealed that our ritual manipulation remained significant: for grief, $F(1,97)=12.22, p=.001$,

$\eta_{p}{ }^{2}=.112$; for perceived control, $F(1,97)=10.25, p=.002, \eta_{p}{ }^{2}=.096$. In both analyses, perceived demand effects was not a significant covariate $\left(F(1,97)<1, p=.86, \eta_{p}{ }^{2}=.000\right.$ and $F(1,97)<1$, $p=.99, \eta_{p}^{2}=.001$, respectively).

\section{Experiment 3: The Power of Performing Rituals}

Using different types of losses and rituals, our first two experiments provide consistent evidence that rituals performed after experiencing a loss increase perceived control and mitigate grief. Experiment 3 explores whether actually performing the actions underlying ritualistic behavior is necessary for the benefits of rituals on perceived control and grief to emerge. We tested this hypothesis in two ways. First, some participants who has just experienced a loss were informed that people often engage in rituals after a loss, but did not perform the ritual; this condition tests whether simple awareness that people commonly use rituals after losses - without actually going through motions of the ritual - has beneficial effects. Second, we added conditions in which participants were told that people often sit in silence after a loss (and again let some participants perform this behavior while others were only informed but did not actually sit in silence); this condition tests whether being informed that any behavior (such as sitting in silence) and then performing that behavior has benefits, or whether information plus an actual ritual is necessary, as our account suggests.

\section{Method}


Participants. One-hundred seventy-two individuals $\left(M_{a g e}=21.44, S D=2.75 ; 47 \%\right.$ male $)$ from a pool of subjects managed by a private university in the northeastern United States participated in the study for pay. As in Experiment 2, participants received a $\$ 15$ show-up fee and had the opportunity to earn an additional \$200.

Design and Procedure. Experiment 3 employed the same general procedures and measures as in Experiment 2, with a few key differences. First, there was no pre-session online survey. Second, rather than having two conditions, Experiment 3 employed two betweensubjects manipulations: 1) information plus action vs. information only; and 2) ritual vs. sitting in silence.

As in Experiment 2, the experimenter first informed participants about the random draw and asked them to write a short essay about why they cared about winning the $\$ 200$ and how they would spend it. After the lottery winner was announced and dismissed from the experiment, the remaining participants were randomly assigned to one of the four experimental conditions. Participants assigned to the information plus action / ritual condition read:

Your next task is to engage in a ritual. Previous research has found that people often engage in rituals after a loss. Please engage in each of the following steps involved in the ritual. Please read the instructions to each step carefully and follow what they asking you to do. The experimenter will let you know when time is up. Step 1: Please draw how you currently feel on the piece of paper on your desk for two minutes; Step 2. Please sprinkle a pinch of salt on the paper with your drawing; Step 3. Please tear up the piece of paper; Step 4. Now please count up to ten in your head five times. Step 5. You have now completed this task.

Participants assigned to the information plus action / sitting in silence condition read:

Your next task is to sit in silence for a few minutes. Previous research has found that people often sit in silence after a loss. The experimenter will let you know when time is up.

Participants assigned to the information only / ritual condition read: 
Previous research has found that people often engage in rituals after a loss. Please click next to move to the next screen.

Participants assigned to the information only / sitting in silence condition read:

Previous research has found that people often sit in silence after a loss. Please click next to move to the next screen.

Participants completed the same measures as in Experiment 2: the 5-item measure of perceived control $(\alpha=.79)$, the 3-item measure of grief $(\alpha=.87)$, and the item assessing demand effects.

\section{Results and Discussion}

Table 2 reports means and standard deviations for all dependent variables by condition.

Perceived control. A 2 (information: information plus action vs. information only) X 2 (action: ritual vs. sitting in silence) between-subjects ANOVA with perceived control as the dependent variable revealed a significant effect of information $(F(1,150)=8.76, p=.004$,

$\left.\eta_{p}{ }^{2}=.055\right)$ and action $\left(F(1,150)=6.68, p=.011, \eta_{p}{ }^{2}=.043\right)$. These main effects were qualified by a significant interaction, $F(1,150)=4.04, p=.046, \eta_{p}{ }^{2}=.026$. Post hoc tests revealed that perceived control was higher in the information plus action / ritual condition than in any of the other three conditions (all $p \mathrm{~s}<.01$ ), and did not significantly differ across these other conditions (all $p \mathrm{~s}>.50$ ).

Grief. A similar 2 X 2 ANOVA with grief as the dependent variable revealed a marginally significant effect of information $\left(F(1,150)=2.93, p=.089, \eta_{p}{ }^{2}=.019\right)$ and no significant effect for action $(p=.23)$. This analysis also revealed the predicted interaction, $F(1,150)=4.48$, $p=.036, \eta_{p}{ }^{2}=.029$. As with perceived control, post hoc tests revealed that grief was lower in the information plus action / ritual condition than in any of the other three conditions (all $p \mathbf{s}<.04$ ), and did not differ across these other conditions (all $p \mathrm{~s}>.52$ ). 
Mediation. Next, we conducted regression analyses to assess whether participants' feelings of perceived control in the information plus action / ritual condition mediated the effects of rituals on reduced grief. We included a dummy variable equal to 1 for the information plus action / ritual condition, and 0 otherwise. The effect of rituals in this condition (compared to all others) was significantly reduced (from $\beta=-.23, p=.004$, to $\beta=-.14, p=.094$ ) when perceived control was included in the equation, and perceived control was a significant predictor of grief $(\beta=-.28, p=.001)$. A bootstrap analysis showed that the $95 \%$ bias-corrected confidence intervals for the size of the indirect effect excluded zero $(-0.67,-0.12)$, suggesting a significant indirect effect (MacKinnon et al., 2007).

Demand effects. As in Experiment 2, participants' belief that the experimenter wanted them to feel better about their loss was not affected by our manipulations (all $p \mathrm{~s}>.43$ ). We conducted two 2 X 2 ANCOVAs with grief and perceived control as the dependent measures while controlling for the question about demand effects. Confirming the results of our primary analyses, these analyses revealed the same significant interactions as above: for grief, $F(1,149)=4.62, p=.033, \eta_{p}{ }^{2}=.030$; for perceived control, $\left.F(1,149)=4.18, p=.043, \eta_{p}{ }^{2}=.027\right)$. In both analyses, perceived demand was not a significant covariate $\left(F_{\mathbf{S}}<1, p s>.52\right)$.

Overall, the results of Experiment 3 provide further support for the positive effect of rituals on perceived control and reduced grief. In addition, they indicate that these effects emerge when performing the actions underlying ritualistic behavior, rather than from simply knowing that people often engage in rituals after experiencing a loss.

\section{General Discussion}

Despite the large body of qualitative data on rituals and their pervasive use in marking both positive and negative life milestones - from births to marriages to deaths - little is known 
about the causal impact of rituals on people's emotional health. Given the profoundly negative impact of grief on both psychological and physical health (Stroebe, Schut, \& Stroebe, 2007), uncovering means by which to alleviate grief is a critical endeavor. Although the specific rituals used to cope with losses vary widely from culture to culture - and indeed our participants reported engaging in a wide variety of rituals themselves - our results suggest that a common psychological mechanism both underlies these different rituals and explains their effectiveness. Engaging in rituals mitigates grief by restoring the feelings of control that are impaired by both life-changing (the death of loved ones) and more mundane (losing lotteries) losses, and rituals are particularly effective when participants actually perform them.

Our research makes three primary contributions. First, our pilot study demonstrates that people use many different - and often contradictory - rituals, indicating that the particular actions people perform when performing rituals are not the primary driver of reduced grief. Second, believing in the effectiveness of rituals did not moderate the relationship between performing rituals and reduced grief (Experiment 2), suggesting that people do not need to explicitly endorse the efficacy of rituals in order for rituals to increased perceived control and lower grief after a loss. Finally, as the results of Experiment 3 show, referring to a set of actions as a "ritual" in addition to performing such actions are both critical ingredients for rituals to be effective: asking participants to sit in silence after telling them that "people often sit in silence after a loss" neither increased perceived control nor reduced grief, whereas performing a ritual that consisted of a series of behaviors after learning that people often engage in rituals after experiencing a loss was effective. Together, these results suggest that rituals appear to be defined by purposeful behaviors designed to achieve some desired outcome, and that the specific 
behaviors that constitute those rituals are less important than performing some form of ritualistic behavior.

In our initial pilot study, we relied on participants' self-definitions of what constitutes a "ritual" - as a result, our investigation encompasses a broad definition of the term, including both actions prescribed by a religion or a community of reference as well as "everyday" rituals chosen by participants and novel rituals designed by the experimenters. Our choice of this broad definition is consistent with evidence that mourning rituals across cultures and religious are often contradictory, suggesting that the effectiveness of rituals on grief after a loss is driven primarily by the act of engaging in a ritual and not by the specific actions involved in the ritual. Future research, however, is needed to explore at a more granular level the impact of specific forms of rituals on mourning. Similarly, specific forms of mourning likely elicit different types of rituals. Indeed, we do not mean to imply that the emotional consequences of losing loved ones and losing lotteries are identical, and the divergent consequences of each type of loss - and which rituals are most effective at assuaging grief for which types of losses - clearly warrant further investigation. At the same time, our results suggest that despite these divergences, rituals serve at least one common purpose across different types of losses, in restoring a lost sense of control.

In Experiments 2 and 3, the rituals we asked participants to perform involved drawing a picture of their feelings on a piece of paper and then ripping that paper into pieces. By performing this particular behavior, participants potentially destroyed a symbolic representation of their loss, which may have contributed to their decreased grief over and above the effect of less symbolic ritualistic behaviors. Future research should examine how incorporating symbolism into ritualistic behaviors may increase the efficacy of rituals in helping people cope with their losses. 
Our findings contribute to the threat-compensation literature examining compensatory behaviors that follow threats, and aversive accompanying states. Proulx and Inzlicht (2012; see also Proulx, Inzlicht, \& Harmon-Jones, 2012) have proposed a meaning-maintenance model which integrates social psychological theories of compensatory behaviors following threats and expectancy violations. Consistent with this model, losses may in fact serve as threats and be experienced as aversive states. People may thus use rituals as a way to compensate for the loss and relieve this aversive arousal. This framework offers the interesting possibility that rituals may involve both cognitive factors - such as perceived control - and also emotional factors: engaging in rituals to cope with losses may also reduce subsequent aversive emotional states. Rituals may not only reduce negative but also increase positive emotions: rituals involved in consumption (such as eating and drinking) can enhance enjoyment due to the greater involvement they prompt in the consumption experience (Vohs, Wang, Gino, \& Norton, in press). Future research that simultaneously examines the role of cognitive and affective factors as both motivators of engaging in rituals and outcomes of having engaged in those rituals would deepen our understanding of the effects of rituals.

Finally, we note that our participants were drawn from non-clinical samples, and our conclusions therefore must be qualified in light of research suggesting that overly ritualistic behavior can negatively impair psychological functions, as in the case of obsessive-compulsive disorder (Tolin, Abramowitz, Przeworski, \& Foa, 2002). As a result, further research is needed to understand which types of rituals benefit which types of individuals. Still, our results offer initial support for Durkheim's contention that "mourning is left behind, thanks to mourning itself" (Durkheim, 1912, p. 299); the rituals of mourning in which our participants engaged hastened the decline of the feeling of mourning that accompanies loss. 


\section{References}

Ai, A. L., Tice, T. N., Peterson, C., \& Huang, B. (2005). Prayers, spiritual support, and positive attitudes in coping with the September 11 national crisis. Journal of Personality, 73, 763791.

Ashenburg, K. (2004). The mourner's dance: What we do when people die. New York: North Point Press.

Brehm, J. W. (1966). A theory of psychological reactance. New York: Academic Press.

Clements, P. T., Vigil, G. J., Manno, M. S., Henry, G. C., Wilks, J., Kellywood, R., Foster, W. (2003). Cultural perspectives of death, grief, and bereavement. Journal of Psychosocial Nursing and Mental Health Services, 41, 18-26.

Cohn, P. J. (1990). Pre-performance routines in sport: Theoretical support and practical applications. Sport Psychologist, 4, 301-312.

Crews, D. J. \& Boutcher, S.H. (1986). An exploratory observational behavior analysis of professional golfers during competition. Journal of Sport Behavior, 9, 51-58.

Durkheim, E. (1912, 2001). The elementary forms of religious life. Oxford: Oxford University Press.

Ellison, C. G., \& Taylor, R. J. (1996). Turning to prayer: Social and situational antecedents of religious coping among African Americans. Review of Religious Research, 38, 111-131.

Fast, N. J., Gruenfeld, D. H., Sivanathan, N., \& Galinsky, A. D. (2009). Illusory control: A generative force behind power's far-reaching effects. Psychological Science, 20, 502508.

Glass, D., \& Singer, J. E. (1972). Behavioral aftereffects of unpredictable and controllable aversive events. American Scientist, 60, 457-465.

Gmelch, G. J. (1971). Baseball magic. Transaction, 8(8), 39-41. 
Kemp, C., \& Bhungalia, S. (2002). Culture and the end of life: A review of major world religions. Journal of Hospice and Palliative Nursing, 4(4), 235-242.

Klein, D. C., Fencil-Morse, E., \& Seligman, M. E. P. (1976). Learned helplessness, depression, and the attribution of failure. Journal of Personality and Social Psychology, 33, 508-516.

Low, S. M. (1994). Embodied metaphors: Nerves as lived experience. In T. J. Csordas (Ed.). Embodiment and experience: the existing ground of culture and self (pp. 139-162). Cambridge, UK: Cambridge University Press.

MacKinnon, D. P., Fairchild, A. J., \& Fritz, M. S. (2007). Mediation analysis. Annual Review of Psychology, 58, 593-614.

Malinowski, B., \& Redfield, R. (1948). Magic, science and religion, and other essays. Boston: Beacon Press.

Nolen-Hoeksema, S., \& Larson, J. (1999). Coping with loss. Mahwah, NJ: Lawrence Erlbaum Associates.

Pargament, K.I. (1997). The psychology of religion and coping: Theory, research, practice. New York: Guilford Press.

Pennebaker, J. W., \& Chung, C. K. (2007). Expressive writing, emotional upheavals, and health. In H. Friedman \& R. Silver (Eds.) Handbook of Health Psychology (pp. 263-284). New York: Oxford University Press.

Prigerson, H. G., Maciejewski, P. K., Reynolds III, C. F., Bierhals, A. J., Newsom, J. T., Fasiczka, A., Frank, E., Doman, J., Miller, M. (1995). Inventory of complicated grief: A scale to measure maladaptive symptoms of loss. Psychiatry Research, 59, 65-79.

Proulx, T., \& Inzlicht, M. (2012). The five “A”s of meaning maintenance: Finding meaning in the theories of sense-making. Psychological Inquiry, 23, 317-335. 
Proulx, T., Inzlicht, M., \& Harmon-Jones, E. (2012). Understanding all inconsistency compensation as a palliative response to violated expectations. Trends in Cognitive Sciences, 16(5), 285- 291.

Rodin, J., \& Langer, E. J. (1977). Long-term effects of a control-relevant intervention with the institutionalized aged. Journal of Personality and Social Psychology, 35, 897-902.

Romanoff, B. D. (1998). Rituals and the grieving process. Death Studies, 22(8), 697-711.

Rook, D. W. (1985). The ritual dimension of consumer behavior. Journal of Consumer Research, 12 (December), 251-264.

Sherkat, D.E., \& Reed, M.D. (1992). The effects of religion and social support on self-esteem and depression among the suddenly bereaved. Social Indicators Research, 26, 259-275.

Strack, F., Schwarz, N., \& Gschneidinger, E. (1985). Happiness and reminiscing: The role of time perspective, affect and mode of thinking. Journal of Personality and Social Psychology, 49, 1460-1469.

Stroebe, M., Schut, H., \& Stroebe, W. (2007). Health outcomes of bereavement. Lancet, 370, 1960-1973.

Stroebe, M. S., Hansson, R. O., Stroebe, W., \& Schut, H. (Eds.) (2001). Handbook of bereavement research: Consequences, coping and care. Washington, DC: American Psychological Association.

Tolin, D. F., Abramowitz, J. S., Przeworski, A., \& Foa, E. B. (2002). Thought suppression in obsessive-compulsive disorder. Behaviour Research and Therapy, 40, 1251-1270.

Turner, V. (1969). The ritual process. Chicago: Aldine.

Van Boven, L., \& Gilovich, T. (2003). To do or to have? That is the question. Journal of Personality and Social Psychology, 85, 1193-1202. 
Vohs, K.D., Wang, Y., Gino, F., \& Norton, M.I. (in press). Rituals enhance consumption. Psychological Science.

Whitson, J. A., \& Galinsky, A. D. (2008). Lacking control increases illusory pattern perception. Science, 322, 115-117. 
Table 1. Examples of rituals (Pilot Study).

\begin{tabular}{|c|c|c|}
\hline & Failed Relationship & Death of Loved One \\
\hline 1 & $\begin{array}{l}\text { I returned alone to the location of the } \\
\text { breakup each month on the anniversary of } \\
\text { the breakup to help cope with my loss and } \\
\text { think things over. }\end{array}$ & $\begin{array}{l}\text { I used to play the song by Natalie Cole "I } \\
\text { miss you like crazy" and cry every time I } \\
\text { heard it and thought of my mom. }\end{array}$ \\
\hline 2 & $\begin{array}{l}\text { I wrote a letter expressing my feelings and I } \\
\text { never mailed it. I destroyed the letter and let } \\
\text { my painful feelings go. }\end{array}$ & $\begin{array}{l}\text { I washed his car every week as he used to } \\
\text { do. }\end{array}$ \\
\hline 3 & $\begin{array}{l}\text { When we were together, I had had special } \\
\text { playlists of happy, romantic music that I/we } \\
\text { would listen to over and over again. After } \\
\text { the breakup, I avoided all places that } \\
\text { reminded me of him and stopped listening to } \\
\text { any songs I had associated with him or a } \\
\text { particular memory of something we had } \\
\text { done. }\end{array}$ & $\begin{array}{l}\text { The ritual involved sitting shiva for a week, } \\
\text { being in what I term "major sloshim" for } \\
\text { thirty days, and being in mourning for a } \\
\text { year. On the anniversary of her death ( } 7 \\
\text { Adar-Hebrew calendar), I say Mourners } \\
\text { Kaddish and El Malei Rachamim (Memorial } \\
\text { Prayer) and light a yarzheit candle. That date } \\
\text { was a week ago. She died } 21 \text { years ago. I } \\
\text { will do this until I die. }\end{array}$ \\
\hline 4 & $\begin{array}{l}\text { I looked for all the pictures we took together } \\
\text { during the time we dated. I then destroyed } \\
\text { them into small pieces (even the ones I } \\
\text { really liked!), and then burnt them in the } \\
\text { park where we first kissed. }\end{array}$ & $\begin{array}{l}\text { I hadn't gone back to her house in fifteen } \\
\text { years. And in these fifteen years, I have been } \\
\text { going to hairdressers to cut my hair every } \\
\text { first Saturday of the month as we used to do } \\
\text { together. }\end{array}$ \\
\hline
\end{tabular}


Table 2. Means (and standard deviations) for the main variables assessed in Experiment 3, by condition.

\begin{tabular}{|c|c|c|c|c|}
\hline & & Demand effect & $\begin{array}{c}\text { Perceived } \\
\text { control }\end{array}$ & Grief \\
\hline \multirow[t]{2}{*}{$\begin{array}{l}\text { Information } \\
\text { only }\end{array}$} & Sitting in silence & $\begin{array}{l}2.72 \\
(1.38)\end{array}$ & $\begin{array}{c}2.87 \\
(1.02)\end{array}$ & $\begin{array}{r}3.44 \\
(1.77)\end{array}$ \\
\hline & Ritual & $\begin{array}{c}2.61 \\
(1.59)\end{array}$ & $\begin{array}{c}2.97 \\
(1.03)\end{array}$ & $\begin{array}{c}3.66 \\
(1.44)\end{array}$ \\
\hline \multirow[t]{2}{*}{$\begin{array}{l}\text { Information } \\
\text { plus action }\end{array}$} & Sitting in silence & $\begin{array}{c}2.55 \\
(1.37)\end{array}$ & $\begin{array}{c}3.03 \\
(0.92)\end{array}$ & $\begin{array}{r}3.54 \\
(1.44)\end{array}$ \\
\hline & Ritual & $\begin{array}{c}2.82 \\
(1.60)\end{array}$ & $\begin{array}{c}3.81 \\
(1.19)\end{array}$ & $\begin{array}{c}2.72 \\
(1.40)\end{array}$ \\
\hline
\end{tabular}

